\title{
Saúde, trabalho e ambiente no meio rural brasileiro
}

\author{
Health, work and environment at the Brazilian rural
}

Frederico Peres ${ }^{1}$

${ }^{1}$ Centro de Estudos da Saúdedo Trabalhador e Ecologia H umana, Escola Nacional deSaúdePública, Fiocruz. Rua Leopoldo Bulhões 1480/29 do CESTEH, M anguinhos. 21041-210 Rio de Janeiro RJ.fperes@fiocruz.br
Abstract This manuscript discusses the implications of the productive paradigm changes in health and environment of rural area of Brazil. It analyzes production, economy and demography data, facing social and structural determinants with health and environmental reflexes, revealing a serious panorama that includes: a) environmental impacts associated to large productivechains, such ascorn, soy-bean, cotton and sugar cane; b) chemical contamination of diverse environment compartments due to pesticides and fertilizers used in agriculture; c) the use of natural land in the expansion of agriculture and cattle farming activities; and d) the reflexes of these actions on individuals, workersor not, that aremoreand moreforced to deal with extreme vulnerability situations because of the risk of rural work processes. Thus, the present article points that macro-determinants (or driven-forces) tends to configure the health status of Rural Brazil inhabitants which, day after day, face a series of challenges in order to guarantee dignity in their work and quality of life.

Key words Rural work, Health, Environment, Production processes
Resumo 0 presenteartigo discute as implicações das mudanças no paradigma produtivo sobre a saúde e o ambiente no meio rural brasileiro. Para tanto, analisa dados de produção, demografia e economia, contrastando os determinantes, de ordem social, estrutural eeconômica, com os reflexos na relação saúde, trabalho eambiente, desvelando um quadro preocupante, que inclui: a) os impactos ambientais de grandes cadeias produtivas como soja, milho, al godão e cana de açúcar; b) a contaminação química de diversos compartimentos ambientais em razão do uso de agrotóxicos efertilizantes na agricultura; c) o uso de áreas naturais para 0 aumento de áreas destinadas à agricultura e pecuária; e d) os reflexos destas ações sobre a saúde deum contingente expressivo de indi víduos, trabalhadores ou não, colocados cada vez mais em situação de extrema vulnerabilidade face aos riscosadvindos dos diversos processos produtivos pre sentes no meio rural brasileiro. Assim, o presente artigo mostra queos macrodeterminantes ( ou grandes forças motrizes) acabam por configurar o retrato da saúde dos habitantes do Brasil Rural que, cotidianamente, enfrentam uma série de desafios para a garantia de uma qualidade de vida e de trabalho digna.

Palavras-chave Trabalhador rural, Saúde, Ambiente, Processos de produção 


\section{Introdução}

Situações determinadas no âmbito das relações entre saúde, trabalho e ambiente são fortemente influenciadas pelo nível de desenvolvimento de uma nação ${ }^{1}$. À medida que um país avança em uma escala de desenvolvimento econômico e social, a dimensão local dos problemas de saúde e ambiente originados nos processos produtivos é superada, tornando mais evidentes situações de ordem regional e global ${ }^{2}$, como os acidentes de trabalho, os acidentes industriais ampliados, as contaminações transfronteiriças e a exposição dos grupos populacionais humanos a contaminantes químicos, entre outros ${ }^{3,4}$.

O Brasil é um país em desenvolvimento e, como tal, convive com situações-problema intermediárias entreo padrão "desenvolvido" (próprios dos países da União Européia e dos Estados Unidos, entre outros) e o "não-desenvolvido" (próprio dos países com desenvolvimento tardio, como alguns do Leste Europeu e da Ásia e grande parte do continente africano ${ }^{3}$. Assim, ao mesmo tempo em que ainda enfrenta graves problemas de ordem local (saneamento, qualidade da água para consumo e a prevalência de doenças infecto-parasitárias), passa a lidar com situações-problema características de países mais desenvolvidos, como aumento na incidência de doenças crônico-degenerativas, aumento dos casos de acidentes detrabalho, contaminações/acidentes químicos ampliados, etc. ${ }^{1}$. Tal fato coloca a necessidade de se considerar os problemas de saúde eambiente enfrentados pela população do campo dentro do processo de desenvolvimento do país $5^{5}$, sobretudo no que diz respeito às formas de organização do trabal ho rural ${ }^{6}$.

Antes de qualquer outra questão, torna-se necessário, aqui, definir o queseentende por rural. No Brasil, o termo rural é mais frequentementeutilizado em contraposição a urbano. N essa visão, segundo o IBGE", "são classificadas como área urbanizada aquela legalmente definida como urbana caracterizada por construções, arruamentos e intensa ocupação humana; as áreas afetadas por transformações decorrentes do desenvolvimento urbano; e aquelas reservadas à expansão urbana". Isso coloca o rural como tudo aquilo externo ao perímetro urbano, o que, na visão de Grabois ${ }^{8}$, faz com que esse espaço seja "definido a partir de carências enão de suas próprias características".

Para Kageyama9, a discussão sobre a definição de rural é praticamente inesgotável, mas parece haver um certo consenso sobre os seguintes pontos: a) rural não é sinônimo de e nem tem ex- clusividade sobre o agrícola; b) o rural é multissetorial (pluriatividade) e multifuncional (funções produtiva, ambiental, ecológica, social); c) as áreas ruraistêm densidadepopulacional relativamente baixa (o que pode mesmo constituir sua própria definição legal); d) não há um isolamento absoluto entre os espaços rurais e as áreas urbanas. Assim, para fins desse trabalho, considera-se rural todo espaço não urbanizado e de baixa densidade populacional, onde se realizam atividades econômicas diversas, as quais têm importante função na organização dos grupos populacionais. Esta definição seaproxima da acima apresentada ${ }^{9}$, sem se contrapor a do IBGE ${ }^{7}$, configurando-sea mais adequada para o trabal ho que aqui se apresenta.

Segundo dados do último Censo Agropecuário ${ }^{10}$, existem cerca de 16,4 milhões de pessoas ocupadas em estabelecimentos rurais, correspondendo a aproximadamente $50 \%$ da população residente em áreas rurais (31,3 milhões de pessoas, segundo a PNAD ${ }^{11}$ ). Tanto a população quanto o número de estabelecimentos localizados em áreas rurais têm decrescido no país desde 1985, confirmando uma tendência migratória em direção aos conglomerados urbanos e áreas periurbanas.

Ainda de acordo com dados apresentados no Censo Agropecuário de $2006^{10}$ e também na PNAD ${ }^{11}$, a população residente nas áreas rurais do país vem decrescendo desdeo ano de 1970, data do primeiro Censo Agropecuário. Em 1970, eram aproximadamente 41 milhões de residentes em áreas rurais, número que no ano de 1980 já caía para pouco mais de 37 milhõese, em 2006, chegou a 31,3 milhões de pessoas ${ }^{10}$. N esse mesmo período, o número de pessoas ocupadas no meio rural mostra dois momentos distintos: a) o primeiro, entre 1970 e 1985, com um aumento da mão-deobra ocupada em áreas rurais de 17,6 milhões de trabalhadores para 23,4 milhões; b) no segundo momento, entre 1985 e2006, ocorreuma inversão nessa tendência, com o número de pessoas ocupadas no meio rural caindo para aproximadamente 18 milhões em 1985 e 16,4 milhões em 2006.

A pesar dessa tendência de queda, tanto no número de habitantes quanto de trabalhadores no meio rural, o país registrou, no mesmo período (1970-2006), um crescente aumento da produtividade agropecuária (tradicionalmente associada às áreas rurais), fruto da otimização e da mecanização dos processos produtivos nessas áreas.

As mudanças do paradigma produtivo rural, ocorridas nos últimos anos, configuram uma situação em que, apesar de concentrar metade da força de trabalho mundial ${ }^{12}$, observa-se um número cada vez menor de trabalhadores, alocados 
em atividades agropecuárias, submetidos a uma gama cada vez maior de riscos ${ }^{6,13-15}$ à sua saúde.

0 presente artigo discute as implicações desse fenômeno sobre a saúdee o ambienteno meio rural brasileiro. Apesar de, na prática, ser impossível dissociar o peso das dimensões saúde, trabalho e ambiente, adota-se aqui, para fins de organização de idéias, uma discussão específica sobre os principais problemas encontrados em cada um das dimensões e, ao final, discute-se as principais implicações para o campo da Saúde Coletiva no país. Configura-se como uma revisão sobre o tema, baseada na análise da literatura de referência presenteem bases dedadosnacionais (Scielo, IBGE, M inistérios da Saúde e da Agricultura) e internacionais (Lilacs, Pubmed e FAO), além de documentos produzidos por instituições ligadas à assi stência ao homem do campo (Emater, Pesagro e Embrapa).

Com este artigo, não se pretende tecer uma discussão aprofundada sobre cada uma das dimensões apontadas e seus impactos sobre a sociedaderural brasileira; pretende-se, apenas, lançar luz sobre alguns dados relevantes referentes às atividades econômicas predominantes no meio rural brasileiro e suas relações com a saúde da população, trabalhadora ou não, e dos ambientes correlatos.

\section{A dimensão do trabalho no meio rural brasileiro}

O agronegócio é, hoje, o maior setor exportador brasileiro, representando 42\% das exportações de nosso país, de acordo com dados do Ministério da Agricultura ${ }^{16}$. É o fiel da balança comercial e a garantia de seu superávit. Ainda segundo essa fonte, o agronegócio representa 33\% do PIB brasileiro e encerra $37 \%$ dos empregos ${ }^{16}$.

N osúltimos anos, observa-se, em grandeparte do meio rural brasileiro, uma mudança do paradigma produtivo tradicional - baseado na agricultura familiar - para a agroindústria de exportação, sobretudo aquela baseada em monoculturaslatifundiárias (soja, milho, al godão, etc.). Esta mudança, fortemente influenciada pela política neoliberal adotada no país desde a década de noventa ${ }^{15}$, tem como mote principal o aumento da produtividade agrícola suportado pelo implemento de novas tecnologias de produção, em especial de agentes químicos utilizados tanto para o controle e o combate a pragas quanto para o estímulo do crescimento de plantas e frutos ${ }^{6}$.

Um dos principais problemas relacionados a estas mudanças no paradigma produtivo rural é a migração ${ }^{17-19}$, fenômeno que pode ser considerado, em nosso país, como reemergente, dada às novas dinâmicas migratórias observadas nos últimos vinte anos, principalmente no que diz respeito a grandes cadeias produtivas de monoculturas, como a soja, o milho e a cana-de-açúcar ${ }^{20}$.

$\mathrm{H}$ á cerca de vinte anos, um intenso fluxo migratório foi registrado partindo da Região Sul do país em direção aos estados do M ato Grosso e M ato Grosso do Sul' ${ }^{21}$. Na busca por terras mais baratas, um grande número de agricultores e pecuaristas deixaram suas terras natais no Sul em direção à Região Centro-O este do país, onde intensificaram o cultivo de gado (principalmente no M ato Grosso do Sul) e de grandes monoculturas, como o milho, o algodão e a soja (principalmente no M ato Grosso ${ }^{21}$ ). Dados da PNAD ${ }^{11}$ mostram quea Região Centro-O este foi o segundo principal destino dos nascidosna Região Sul que resolveram migrar nosúltimos vinte anos. Segundo essa mesma fonte, 5\% de toda a população residente na Região Centro-O este é natural de estados da Região Sul do país. Também esta região (Centro-Oeste) foi a segunda mais escolhida pelos naturais da Região Nordeste (que correspondem a 12,3\% dos residentes da Região Centro-O este) e a primeira escolha dos naturais da Região Norte $(2,2 \%$ dos residentes da região) que, neste período, migraram de seus estados de origem ${ }^{11}$.

Grande parte dos migrantes das regiões Sul e N ordeste instalados na Região Centro-O este esteve ocupada, nos últimos anos, com os cultivos da soja, milho e algodão.

Aqueles que já possuíam terras em seus estados de origem e que, com a venda, conseguiram investir em novas propriedades nessa região, acabaram por conseguir uma inserção mais vantajosa no processo produtivo, e hoje formam a eliterural deseus estados emunicípios ${ }^{21}$. Jáaqueles que migraram com a promessa de empregos nos sítios e fazendas de outrem, hoje vivem os reflexos de uma inserção marginal nessa cadeia produtiva, cada vez mais mecanizada e restritiva a novos postos de trabalho. Como principal desdobramento desse fenômeno, observa-se a formação de um excedente de mão-de-obra sem destinação conhecida. Segundo Benjamin ecolaboradores ${ }^{22}$, A desestruturação da policultura tradicional, que propiciava uma ocupação estável da terra, foi feita sem alteração da estrutura de propriedade. Em seu lugar, não surgiu uma moderna agricultura baseada na pequena produção, quetambém seria capaz de assegurar a ocupação estável da terra. Como consequência, reduziram-se as oportunidades de emprego, por causa da crescente me- 
canização, e aumentou a urbanização da própria população empregada na agropecuária, com a expulsão dos trabalhadores residentes no campo.

Em outra seção, discutiremos alguns dos impactos desse fluxos migratórios sobre a saúde da população rural, em particular no país.

No que tange à agricultura familiar, também se observa, nos últimos anos, uma mudança nos processos produtivos, principalmente associada à intensificação da produtividade, à diminuição do pessoal ocupado nessas atividades eà pluriatividade (coexistência de diversas atividades produtivas em uma mesma propriedade ${ }^{13}$ ).

Segundo o IBGE ${ }^{10}, 73 \%$ do pessoal ocupado no meio rural brasileiro têm laços de parentesco com o proprietário da terra. Este dado aponta para o fato da maioria da atividade econômica no meio rural brasileiro ser do tipo "familiar". Ademais, a diversidade de atores e segmentos abrangidos por esta classificação (agricultura familiar), como destaca Schneider ${ }^{13}$, é outro fator complicador, quando da opção de uso desse termo para discutir um conjunto de atividades que têm espaço no meio rural brasileiro: Diante dos desafios que o sindicalismo rural enfrentava nesta época - impactos da abertura comercial, falta de crédito agrícola e queda dos preços dos princi pais produtos agrícolas de exportação - , a incorporação e a afirmação da noção de agricultura familiar mostrou-se capaz de oferecer guarida a um conjunto de categorias sociais, como, por exemplo, assentados, arrendatários, parceiros, integrados à agroindústrias, entre outros, que não mais podiam ser confortavelmente identificados com as noções de pequenos produtores ou, simplesmente, de trabalhadores rurais.

Por essa razão, coloca-se aqui a necessidade dedefinir o queseentende, nesseartigo, por agricultura familiar. Para fins da discussão que se segue, considera-se, no presente artigo, agricultura familiar aquela que remonta à lógica campesina de produção, com a participação quase que exclusiva da mão-de-obra familiar, com opção clara pela policultura e que tenha base em pequenas e médias propriedades.

O impacto da mecanização e do implemento deinsumos químicos na agricultura familiar, nos últimos quarenta anos, produziram não apenas um incremento da produção agrícola nacional, mas também possibilitaram a emergência de novas formas de organização do trabalho na agricultura familiar, como as parcerias e os arrendamentos (meeiros, etc.) o que, segundo Alessi eN avarro ${ }^{23}$, leva a um novo momento dessa agricultura familiar, marcado pela "extensão da jornada de trabalho, intensificação do seu ritmo, pagamento por produção, decréscimo real do valor dos salários e descumprimento de direitos trabal histas".

Também leva a um aumento significativo da exposição desses grupos populacionais a diversos agentes químicos perigosos, como os agrotóxicos. N enhum outro grupo é mais vulnerável aos efeitos nocivos dos agrotóxicos que os trabal hadores da chamada "agricultura familiar"24${ }^{26}$. Isso se dá em razão de diversos determinantes, dentre os quais: a) a baixa assistência técnica recebida por estes indivíduos para o manuseio correto desses agentes químicos, agravada pelo fato de, em algumas localidades, essa assistência ser prestada exclusivamente por técnicos ligados ao comércio de agrotóxicos ${ }^{27}$; b) as práticas exploratórias de venda desses insumos químicos, que ignoram qualquer alternativa de controle de pragas menos agressivas à saúde e ao ambiente ${ }^{28}$; c) a não-clareza de informações contidas nos rótulos e bulas de agrotóxicos, associada aos baixos índices de escolaridade observados nesse grupo ${ }^{29}$; d) a pressão recebida para a entrega de um produto aparentemente perfeito, mesmo que, para isso, desconsiderem-se os períodos de carência e as indicações de dosagem durante as pulverizações ${ }^{28}$; e) a pressão exercida pelos proprietários de terra sobre os parceiros (meeiros, arrendatários, etc.) para que se reproduza o uso desses insumos nas áreas arrendadas, mesmo que essa pressão não venha acompanhada da devida orientação técnica ${ }^{24}$; ef) a carência observada nos mecanismos de controle e fiscalização sobre a comercialização, ven da e descarte desses agentes químicos por pequenos produtores ${ }^{27}$.

\section{A dimensão da saúdeno meio rural brasileiro}

As mudanças no mundo do trabalho e nas dinâmicas migratórias no meio rural brasileiro, anteriormente sumarizadas, têm impactos diretos e indiretos na saúde dos diversos grupos populacionais ali residentes ${ }^{30}$. Diversos são os determinantes desses impactos, que vão desde grandes macrodeterminantes, de ordem estrutural, até outros mais específicos, pontuais, intermediários nesse processo de determinação social ${ }^{31}$.

As grandes forças motrizes (ou macrodeterminantes) do processo saúde-doença no meio rural brasileiro, hoje, estão fortemente associadas a políticas governamentais de incentivo a determinadas cadeias produtivas, como as da cana-de-açúcar e da soja ${ }^{20}$.

0 incentivo à produção de etanol é, hoje, uma das principais políticas (nacional e internacio- 
nal) do governo brasileiro, cuja origem remonta a um programa governamental de 1975 (o PróÁlcool). Segundo M asiero e Lopes ${ }^{32}$, O s esforços de investigação de novas formas de energia alternativa têm sido orientados pelo aumento da demanda por biocombustíveis que se caracteriza por: a) aumentos contínuos do preço do petróleo que hojeéa principal fonte primária de energia edevido a sua crescente utilização tem causado o encarecimento das matrizes energéticas de várias nações dependentes da commodity, desencadeando sérios desequilíbrios em suas balanças comerciais; b) benefícios quea expansão da utilização dos biocombustíveis pode trazer para o setor agrícola por meio da implantação de projetos espeć́ficos para fins energéticos com o objetivo de promover 0 desenvolvimento regional sustentável; e, c) redução das emissões de gás carbônico que além do benefício em si poderá ser fonte de ganhos no mercado de carbono uma vez quea parcela de gases não emitidos por um país poderá ser comercializada na forma de créditos a outro participanteinteressado em não reduzir suas emissões.

Focaliza-se aqui o segundo aspecto. Tendo como força motriz o incentivo agrícola para fins energéticos, aumenta-se a produção de cana-deaçúcar no país, processo produtivo que encerra uma série de técnicas e práticas nocivas à saúde dos trabal hadores envolvidos. Além do trabal ho em ambiente externo, comum a quase toda atividade agrícola, o processo de trabalho na coIheita da cana compreende: a) deslocamento pre cário de trabalhadores em caçambas de caminhões ("pau-de-arara"); b) queimada da cana em etapa imediatamenteanterior ao corte; c) movimentos repetitivos com enxadas efoices para o corte da cana, associados à postura inadequada (posição arqueada e frequentes subidas e descidas); d) exposição a animais peçonhentos localizados entre as varas de cana; e) transporte de grande quantidade de varas de cana entre o local de corte e o caminhão que as conduzirá aos engenhos, poden do chegar a quatorze toneladas em um único dia ${ }^{23}$.

Segundo dados do IBGE ${ }^{33}$, entre 1989 e 1996, com a retomada da produção deálcool para uso, em larga escala, como combustível, a produção de cana-de-açúcar no país aumentou de $171 \mathrm{mi}$ Ihões de toneladas (plantados em dois milhões dehectares) para 248 milhões detoneladas ( plantados em quase três milhões de hectares) somente nos estados do Paraná, São Paulo, Santa Catarina eDistrito Federal. Dadosmais recentes desse instituto mostram que, no ano de 2007, a produção nacional de cana-de-açúcar alcançou aproximadamente 550 milhões de toneladas em pou- co mais de sete milhões de hectares plantados ${ }^{11}$, com estimativa de crescimento de $17 \%$ para o ano seguinte (dados não computados até o momento).

Segundo Oliveira ${ }^{34}$, no ano de 2007, havia aproximadamente 585 mil trabal hadores ocupados nas lavouras de cana-de-açúcar em todo o país, sendo 340 mil no eixo Centro-Sul (São PauIo, M inas Gerais, M ato Grosso do Sul e Paraná) e 245 mil no eixo Norte-Nordeste (do litoral N orte da Bahia ao M aranhão).

Ainda segundo a autora, de 1992 a 2007, houve uma queda de $24 \%$ no número de pessoas ocupadas nessa atividade. No mesmo período, segundo dados do IBGE ${ }^{11}$, houve um aumento de aproximadamente $40 \%$ da área cultivada (de 4,2 para sete milhões de hectares) com essa lavoura no país e um aumento de quase $50 \%$ na produção (de 271 para aproximadamente 550 milhões de toneladas). Estes dados, quando contrastados, podem indicar uma situação de vulnerabilidade para esses agricultores ( menos agricultores produzindo mais em condições mais precárias de trabalho), mesmo considerando o aumento da tecnificação do processo produtivo rural. Tal situação vem sendo corroborada por outros estudos sobre 0 tema ${ }^{23}$,35, assim como por alguns indicadores, como os dados do $\mathrm{M} \mathrm{i-}$ nistério da Previdência Social ${ }^{36}$, os quais mostram que, no ano de2006, o número deacidentes de trabalho no processo produtivo da cana-deaçúcar ultrapassou o da construção civil, setor que, historicamente, liderava no país o ranking desse tipo de acidente.

No que tange à exposição de agricultores e consumidores aos agrotóxicos utilizados na cadeia da soja, ainda é cedo para conhecer o seu real impacto, principalmente quanto ao glifosato. Isto se dá em função da baixa toxicidade aguda desseagentequímico (glifosato) edas incertezas sobre os seus mecanismos de ação no organismo humano.

Diversos estudo $\mathrm{s}^{37-40}$, entretanto, vêm apontando para os possíveis efeitos tóxicos da exposição crônica ao glifosato, um herbicida não-seletivo, a problemas de saúde, como dermatites, desregulação do ciclo celular e, principalmente, disrupção endócrina.

Disruptores endócrinos são agentes que, ao serem absorvidos pelo organismo, mimetizam ou bloqueiam hormônios e alteram as funções orgânicas normais (fenômeno conhecido por disrupção). Estas alteraç̧ões (ou disrupções) podem ser de diversas naturezas, tais como o estímulo à produção de hormônios ${ }^{37}$, a alteração nos níveis normais dessas substâncias ${ }^{38}$ ealtera- 
ções no mecanismo de transporte desses hormônios ${ }^{39}$, entre outros. Alguns autores como Benachour e colaboradore ${ }^{40}$ têm afirmado que os efeitos tóxicos do glifosato, incluindo a disrupção endócrina, podem estar sendo subestimados ao não se levar em conta sua interação com adjuvantes presentes nas formulações (bem como com outros princípios ativos usados concomitantemente a estes), levando a graves erros na elaboração de políticas regulatórias.

Com relação às implicações dos fluxos migratórios de trabalhadores rurais sobre a saúde humana, diversos autores vêm destacando os efeitos dessefluxos sobrea incidência de doenças sexualmente transmissíveis, em particular HIV/ aids ${ }^{41,42}$, e outras doenças transmissíveis, como a tuberculose ${ }^{43}$, difteria ${ }^{44}$ e malária ${ }^{45}$.

M onteiro e colaboradores ${ }^{46}$, em recente estudo sobre a distribuição da leishmaniose no país, reforçam a importância dos novos fluxos migratórios associados ao trabalho rural, principalmentenas cadeias da soja eal go dão e da canade açúcar, como um dos principais determinantes da prevalência dessa doença no sul do país. Outros autores, como Silva e colaboradore ${ }^{20} \mathrm{e}$ Rossini ${ }^{47}$, destacam os impactos da atividade canavieira sobre a condição de saúde dos trabal hadores rurais, incluindo: a) os casos de intoxicações por agrotóxicos; b) o desgaste físico decorrente do corte e do transporte da cana, que leva os trabalhadores a situações extremas como a desidratação e a fadiga, além de problemas ergonômicos emusculares (esforço repetitivo no corte); c) os problemas respiratórios associados às queimadas, necessárias na etapa pré-colheita; e d) o aumento dos indicadores de violência nas regiões que abrigam esses trabal hadores migrantes no período da colheita da cana.

Assim, a questão da migração e seus impactos sobre a saúde se configuram como alguns dos principais desafios para a saúde do homem do campo, devido à complexidade de fatores envolvidos e o desafio territorial que se configura em nosso país.

\section{A dimensão ambiental no meio rural brasileiro}

Segundo dados dos últimos censos agropecuários realizados no país (entre 1970 e 2006 foram realizados seis), o tamanho da área destinada a lavouras no país mais que dobrou nos últimos quarenta anos, passando de aproximadamente 34 milhões de hectares em 1970 para 76 milhões em $2006^{10}$. I sto representa a incorporação deáreas naturais (florestas, cerrados, campos, etc.) para esse fim, uma vez que a área destinada a pastagens também aumentou (de pouco mais que 154 milhões de hectares em 1970 para 172 milhões em 2006).

Estes dados contrariam o discurso vigente entre os defensores do grande agronegócio exportador, que afirma que 0 aumento das áreas destinadas ao plantio dessas monoculturas é representado pela incorporação de áreas anteriormente destinadas à pecuária, e não de áreas naturais. Outros dados, como o do programa de pesquisa "Agricultura e Meio Ambiente" ${ }^{48}$, desvelam essa situação eapontam para um dos principais problemas ambientais hoje observados no meio rural brasileiro, representado pela incorporação de áreas naturais à cadeia das grandes monoculturas e a perda da biodiversidade a estes processo relacionada: 0 aumento da área plantada com soja no Brasil resultou na incorporação de terras virgens à produção, bem como na substituição de outros cultivos por soja. Além disso, práticas inadequadas de cultivo intensivo provocaram séria degradação ambiental, como a erosão ea perda de solos férteis, 0 assoreamento ea poluição de importantes cursos d'água, o desaparecimento de nascentes e a perda de biodiversidade ${ }^{48}$.

Dados recentes da publicação "Indicadores de Desenvolvimento Sustentável" 49 mostram que áreas de cerrado e da Floresta Amazônica continuam a ser derrubadas para dar lugar à produção de soja, contribuindo para a degradação ambiental e a diminuição da biodiversidade no país.

$E$ tal fato tende a se agravar desde a publicação, em 14 de outubro de 2004, da M edida Provisória 223/04, queliberou, no país, o plantio de sementes de soja geneticamentemodificadas. Isto é particularmente preocupante (e, aqui, sem levar em consideração todos os potenciais riscos relacionados com a disseminação, na natureza, de plantas geneticamente modificadas), uma vez que a principal semente de soja geneticamente modificada que se tem disponível no mercado tem, por característica principal, ser resistente a um tipo específico de herbicida, o glifosato.

Esta característica acarretou, nos Estados Unidos, um aumento da quantidade de herbicida utilizado por área plantada de soja, conforme dados do Departamento de Agricultura daquele paí $5^{50}$, num percentual de aproximadamente $250 \%$ em apenas três anos (de 1996, ano em que a Soja RR começou a ser plantada naquele país, a 1998). Tal fato foi responsável por, nos dias de hoje, a Soja RR ocupar aproximadamente $90 \%$ de toda a área destinada ao plantio de soja nos Estados Unidos e o glifosato corresponder a 94\% 
do consumo de todos os agrotóxicos utilizados neste cultivo (Figura 1 ).

De acordo com o programa de pesquisa "Agricultura e M eio Ambiente", patrocinado pela WWF ${ }^{48}$, somente a cadeia da soja no Brasil movimenta aproximadamente US $\$ 32$ bilhões anualmenteeemprega cerca de 5,4 milhões de pessoas. A década de 1990-2000 foi a década da expansão da soja (Figura 2 A) e, por esta razão, destaca-se aqui o papel dessa cadeia produtiva sobre o ambiente (em particular sobre o cerrado bra- sileiro, região que concentra a maior parte das plantações de soja no país).

o Brasil é, hoje, o maior produtor mundial de soja do mundo, cuja produção é, basicamente, destinada à exportação. A opção do governo brasileiro pela produção de soja, como uma commodity, tem trazido uma série de agravos ao ambiente, não apenas aqueles relacionados ao desmatamento e à destruição do cerrado brasileiro, ondese concentra a mai oria das plantações de soja no país, mas também ao uso extensivo de agrotóxicos, sobretudo herbicidas (Figura 2 B).

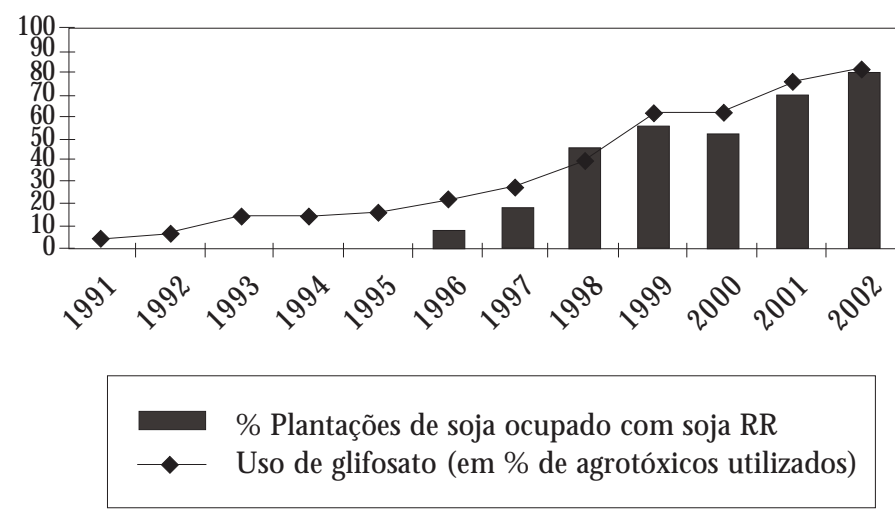

Figura 1. U so de sementes geneticamente modificadas e consumo de glifosato nos Estados U nidos.

Fonte: USDA (2003).

\section{A - Produção de soja - Brasil}

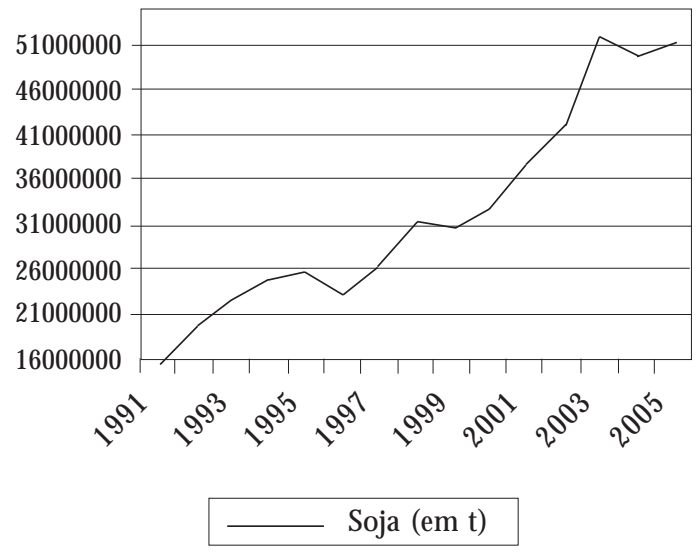

B - Consumo de herbicidas - Brasil

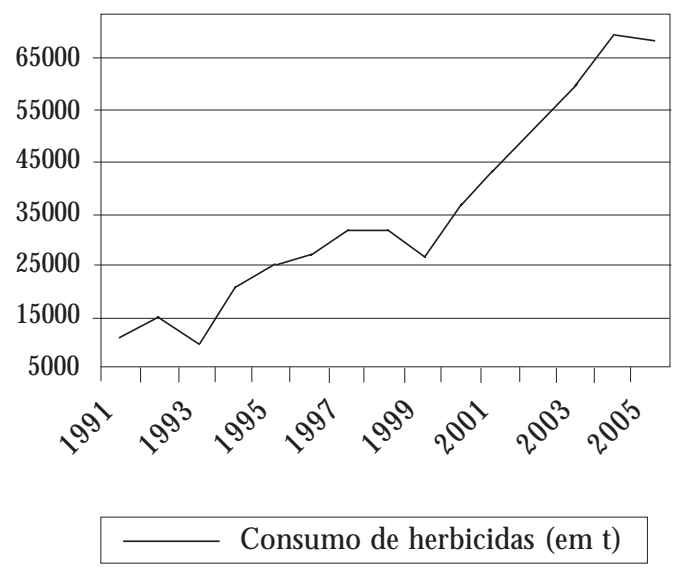

Figura 2. Produção de soja no país e consumo de herbicidas, 1991-2005.

Fonte: FAOSTAT (2005). 
No país, já se pode observar os efeitos do uso de soja geneticamente modificada sobre o consumo de agrotóxicos. Em reportagem publicada pelo jornal Valor Econômico de 23/04/200751, foram apresentados dados do Instituto Brasileiro do M eio Ambiente (IBAMA) que mostram um aumento de $95 \%$ do consumo de glifosato no país, de 2000 a 2005, acompanhado de um aumento de $71 \%$ das áreas ocupados com a soja (no mesmo período). Estes dados derrubam dois dos principais argumentos dos grupos defensores do plantio da soja transgênica: a) o primeiro, que a soja transgênica diminuiria o uso de agrotóxicos; e b) o segundo, que com o aumento na produtividade, potencialmente provocado pela soja transgênica, se diminuiria o uso de novas áreas para o plantio da soja.

\section{Consideraçõesfinais}

Os dados apresentados e discutidos no presente artigo colocam um problema intrigante para a Saúde Coletiva brasileira: que tipo de esforços empreender quando todas as escolhas possíveis são inadequadas? Explica-se:

a) se os trabalhadores rurais optarem pelo uso de insumos químicos perigosos, como os agrotóxicos, em suas lavouras, podem impulsionar a produtividade e permanecer, mesmo que marginalmente, em uma posição competitiva no mercado global; se não, estão fora do trabalho. Entretanto, ao optar pelo uso deagrotóxicos (entre outros insumos químicos), e assim manter a viabilidade econômica de seus produtos, aumentam sua exposição aos efeitos nocivos destes agentes químicos;

b) estes mesmos trabalhadores, ao tentarem o uso de técnicas alternativas de controle de pragas, projetadas para reduzir a carga química em suas colheitas, introduzem um elemento do risco, visto que boa parte destas práticas não é bem calibrada ao solo e às circunstâncias climáticas locais;

c) a alternativa demigrar em direção aos centros urbanos é opção válida; entretanto, a experiência Ihes diz que as incertezas são grandes e as sustentações sociais são poucas. É importante real çar, ainda, que com exceção de alguns grandes exportadores, a agricultura próxima dos grandes centros é de pequeno porte e uma atividadeeminentementefamiliar, permitindo muito pouco espaço de inserção desse contingente de trabalhadores que deixa o trabalho nas grandes monoculturas.

0 excedente de mão-de-obra nas grandes monoculturas é tal que, se um trabalhador empregado desejar evitar sua exposição aos agrotóxicos, isto significa que está fora de trabalho e que já há alguma outra pessoa imediatamente atrás dele na fila, a espera para ingressar naquele mesmo trabalho perigoso.

$\mathrm{H}$ oje, os principais determinantes do quadro das relações entresaúde, trabalho e ambienteparecem estar relacionados às grandes forças motrizes representadas pelas políticas governamentais de incentivo a determinadas cadeias produtivas. A busca pela garantia do superávit nas trocas comerciais acaba por determinar o estímulo à produção de grandes monoculturas exportadoras, como a soja, o milho e o algodão.

Por outro lado, a necessidade de garantir, no mercado internacional, a supremacia tecnológica sobre a produção deálcool combustível acaba por determinar o aumento da produção e das áreas disponíveis à cultura decana-de-açúcar em diversas regiões do país.

A principal consequência desse processo, como visto no presente artigo, é o predomínio, no país, das grandes cadeias de monoculturas exportadoras e do uso de áreas naturais para esses cultivos, levando à concentração de terra e expondo uma gama de trabalhadores a inúmeros riscos, caracterizando um importante quadro devulnerabilidadesocial eambiental no meio rural brasileiro.

Além disso, como foi possível observar, a contaminação química associada aos processos produtivosse caracteriza como um dosmaiscomplexos problemas de saúde pública e ambiental no país, em razão da diversidade de determinantes envolvidos, da dimensão territorial do país e da deficiência nas estruturas de vigilância correlatas.

Assim, os macrodeterminantes aqui apresentados e discutidos acabam por configurar o retrato da saúde de um contingente expressivo de trabal hadores e não trabalhadores, habitantes do Brasil Rural que, cotidianamente, enfrentam uma série de desafios para a garantia de uma qualidade devida edetrabalho digna. A opção econômica não deve sobrepujar à primazia da garantia dessas condições dignas de trabal ho e saúde. Esse éo verdadeiro desafio colocado para o campo da Saúde Pública, eque deve ser encarado por todos - profissionais da saúde, gestores, técnicos e pesquisadores - no cotidiano de suas atividades. 


\section{Referências}

1. Tambellini AT, Câmara VM . A temática saúde e ambiente no processo de desenvolvimento do campo da saúde coletiva: aspectos históricos, conceituais e metodológicos. Cien Saude Colet 1998; 3(2): $47-59$.

2. Funtowicz S, Ravetz J. Ciência pós-normal e comunidades ampliadas de pares face aos desafios ambientais. $\mathrm{H}$ ist. cienc. saude- $\mathrm{M}$ anguinhos1997; $4(2): 219-230$.

3. Corvalan CF, Kjellstrom T, Smith KR. Health, environment and sustainable development: identifying links and indicators to promote action. Epidemiology 1999;10(5):656-660.

4. Black H. Environmental and public health: pulling together the pieces. Environ Health Perspect 2000; 108:A513-A515.

5. Krieger $\mathrm{N}$. Theories for social epidemiology in the 21st century: an ecosocial perspective. Int J Epidemiol 2001; 30(4):668-677.

6. Graziano da Silva J, Del Grossi M, Campanhola C. 0 que há de realmente novo no rural brasileiro? Cadernos de Ciência \& Tecnologia 2002; 19(1):37-67.

7. Instituto Brasileiro de Geografia e Estatística. Manual de Delineamento dos Setores Censitários de 2000. [site da Internet]. [acessado 2009 mai 11]. Disponível em: http://biblioteca.ibge.gov.br/visualizacao/ instrumentos_de_coleta/doc0210.pdf

8. Grabois J. Que urbano é esse? O habitat num espaço de transição do norte de Pernambuco. Estudos Avançados 1999; 13(36):79-104.

9. Kageyama A. Desenvolvimento rural: conceito e um exemplo de medida. [acessado 2009 mai 11]. Disponível em: http://www.sober.org.br/palestra/12/ 120506.pdf

10. Instituto Brasileiro de Geografia e Estatística. Censo Agropecuário de 2006 - Resultados Preliminares. [acessado 2009 mai 11]. Disponível em: http:// www.ibge.gov.br/home/estatistica/economia/agropecuaria/censoagro/2006/tabela1_1.pdf

11. Instituto Brasileiro de Geografia e Estatística. PNAD - Pesquisa Nacional por Amostras de Domicílios/2007. [acessado 2009 mai 11]. Disponível em: http://www. ibge.gov.br/home/estatistica/populacao/trabalho erendimento/pnad2007/brasil/tab1_1.pdf

12. Maroni M, Fanetti AC, Metruccio F. Risk assessment and management of occupational exposure to pesticides in agriculture. M ed Lav 2006; 97(2):430-437.

13. Schneider S. Teoria social, agricultura familiar e pluriatividade. Rev. bras. Ci. Soc. 2003; 18(51):99-122.

14. Soares WL, Freitas EAV, Coutinho JAG. Trabalho rural e saúde: intoxicações por agrotóxicos no município de Teresópolis - RJ. Rev. Econ. Sociol. Rural 2005; 43(4):685-701.

15. Wolford W. Agrarian moral economies and neoliberalism in Brazil: competing worldviews and the state in the struggle for land. Environment and Planning A 2005; 37(2):241-261.

16. Brasil. Ministério da Agricultura, Pecuária e Abaste cimento. Plano Agrícola e Pecuário 2004/2005. [acessado 2009 mai 11]. Disponível em: http://www. agricultura.gov.br/pls/portal/docs/PAGE/M APA/ PLAN OS/PAP_2004_2005/DEGRAVA \%C7AO\%20 PLAN 0\%20SAFRA\%20RR\%201806.PDF
17. Alves $E$, Lopes MR, Contini E. O empobrecimento da agricultura brasileira. Revista de Política Agrícola 1995; 8(3):15-29.

18. Abramovay R. Agricultura familiar e desenvolvimento territorial. Revista da Associação Brasileira de Reforma Agrária 1998; 28(1):49-67.

19. Camarano AA, Abramovay R. Êxodo rural, envelhecimento e masculinização no Brasil: panorama dos últimos 50 anos [texto para discussão 621]. Rio de Janeiro: IPEA; 1999.

20. Silva JM, N ovato-Silva E, Faria HP, Pinheiro TMM. Agrotóxico e trabalho: uma combinação perigosa para a saúde do trabalhador rural. Cien Saude Colet 2005; 10(4):891-903.

21. Goettert JD. 0 Espaço e o Vento: olhares da migração gaúcha para M ato Grosso de quem partiu e de quem ficou. Dourados: Editora da UFGD; 2008.

22. Benjamin $C$, organizador. A opção brasileira. Rio de Janeiro: Contraponto; 1998.

23. Alessi NP, Navarro VL. Saúde e trabalho rural: 0 caso dos trabalhadores da cultura canavieira na região de Ribeirão Preto, São Paulo, Brasil. Cad Saude Publica 1997; 13(Supl. 2):111-121.

24. Neves D. Agricultura familiar: questões metodológicas. Revista da Associação Brasileira de Reforma Agrária 1995; 25:21-37.

25. Schneider S. Agricultura familiar e industrialização: pluriatividade e descentralização industrial no Rio Grande do Sul. Porto Alegre: Editora da UFRGS; 1999.

26. Guanziroli $C$, Romeiro A, Buanain AM, Sabato AD, Bittencourt G. Agricultura familiar e reforma agrária no século XXI. Rio de Janeiro: FAO/M DA/Garamond; 2001.

27. Moreira JC, Jacob SC, Peres F, Lima JS, Meyer A, Oliveira-Silva JJ, Sarcinelli PN, Batista DF, Egler M, Faria M VC, Araújo AJ, Kubota AH, Soares MO, Alves SR, Moura CM, Curi R. Avaliação integrada do impacto do uso de agrotóxicos sobre a saúde humana em uma comunidade agrícola de Nova Friburgo/RJ. Cien Saude Colet 2002; 7(2):299-311.

28. Peres F, Oliveira Silva JJ, Della-Rosa HV, Lucca SR. Desafios ao estudo da contaminação humana e ambiental por agrotóxicos. Cien Saude Colet 2005; 10(Supl.) :27-37.

29. Peres F, Rozemberg B, Alves SR, Moreira JC, Oliveira-Silva JJ. Comunicação relacionada ao uso de agrotóxicos em uma região agrícola do Estado do Rio de Janeiro. Rev. Saude Publica 2001; 35:564-570.

30. Navarro Z. Desenvolvimento rural no Brasil: os limites do passado e os caminhos do futuro. Estud. Av. 2001; 15(43):83-100.

31. Drachler M L, Cortes SM V, Castro JD, Leite JCC. Proposta de metodologia para selecionar indicadores de desigualdade em saúde visando definir prioridades de políticas públicas no Brasil. Cien Saude Colet 2003; 8(2):461-470.

32. Masiero G, Lopes H. Etanol e biodiesel como recursos energéticos alternativos: perspectivas da América Latina e da Ásia. Rev. bras. polít. int. 2008; 51(2):60-79. 
33. Instituto Brasileiro de Geografia e Estatística. Previsão e A companhamento de Safras nos Estados de São Paulo, Paraná, Santa Catarina e no Distrito Federal. [acessado 2009 mai 18]. Disponível em: http://www.ibge. gov.br/home/estatistica/economia/agropecuaria/ estatisticas_previsao_safras/Previsao_safras.pdf

34. Oliveira F $\bar{C} R$. O cupação, emprego e remuneração na cana-de-açúcar e em outras atividades agropecuárias no Brasil, de 1992 a 2007 [dissertação]. São Paulo (SP): Universidade de São Paulo; 2009.

35. Teixeira M LP, Freitas RM V. Acidentes do trabalho rural no interior paulista. São Paulo Perspec. 2003, 17(2):81-90

36. Brasil. M inistério da Previdência Social. Anuário Estatístico dos Acidentes de Trabalho 2007. Brasília: M inistério da Previdência Social; 2008.

37. Hokanson R, Fudge R, Chowdhary R, Busbee D. Alteration of estrogen-regulated gene expression in human cells induced by the agricultural and horticultural herbicide glyphosate. Hum Exp Toxicol. 2007; 26(9):747-752.

38. Daruich J, Zirulnik F, Gimenez MS. Effect of the herbicide glyphosate on enzymatic activity in pregnant rats and their fetuses. Environ Res. 2001 85(3):226-231.

39. Richard S, Moslemi S, Sipahutar H, Benachour N, Seralini GE. Differential effects of glyphosate and roundup on human placental cells and aromatase Environ Health Perspect. 2005; 113(6):716-720.

40. Benachour N, Sipahutar H, Moslemi S, Gasnier C Travert C, Séralini GE. Time- and dose-dependent effects of roundup on human embryonic and placental cells. Arch Environ Contam Toxicol. 2007; 53(1):126-133.

41. Li L, Morrow M, Kermode M. Vulnerable but feeling safe: HIV risk among male rural-to-urban migrant workers in Chengdu, China. AIDS Care 2007; 19(10):1288-1295

42. Suwanvanichkij V. Displacement and disease: The Shan exodus and infectious disease implications for Thailand. Confl Health. 2008; 2(4).

43. Rees D, Murray J, Nelson G, Sonnenberg P. Oscillating migration and the epidemics of silicosis, tuberculosis, and HIV infection in South African gold miners. Am J Ind M ed. 2009. [Epub ahead of print]
44. Curtis S. In-migration and diphtheria mortality among children in the Sundsvall region during the epidemics of the 1880s. J Hist M ed Allied Sci. 2008; 63(1):23-64

45. Gómez-Dantés $H$, Birn AE. Malaria and social movements in M exico: the last 60 years. Parassitologia 2000; 42(1-2):69-85.

46. Monteiro WM, Neitzke HC, Lonardoni M VC, Silveira TGV, Ferreira MEMC, Teodoro U. Distribuição geográfica e características epidemiológicas da leishmaniose tegumentar americana em áreas de colonização antiga do Estado do Paraná, Sul do Brasil. Cad Saude Publica 2008; 24(6):1291-1303.

47. Rossini RE. O trabalho da mulher na agricultura canavieira altamente tecnificada e capitalizada São Paulo - Brasil. In: Lemos AIG, Arroyo M, Silveira $M L$, organizadores. América Latina: cidade, campo e turismo. São Paulo: Clacso; 2006.

48. WWF. Programa Agricultura e M eio Ambiente. [site da Internet]. [acessado 2008 dez 15]. Disponível em: http://www.wwf.org.br/projetos/default.asp? module=tema/programa agricultura.htm

49. Instituto Brasileiro de Geografia e Estatística. Indicadores de Desenvolvimento Sustentável - Brasil 2008. [acessado 2009 mai 11]. Disponível em: http://www. ibge.gov.br/home/geociencias/recursosnaturais/ids/ default.shtm

50. Fernandez-Cornejo J, M cBride W. Genetically Engineered Crops for Pest M anagement in the US [Agricultural Economics Report No. 786]. Washington, D.C.: USDA; 2000.

51. Zanatta M. Soja transgênica eleva a aplicação de agrotóxicos. Jornal Valor Econômico 2005; 23 abr.

Artigo apresentado em 10/06/2009

Aprovado em 20/07/2009

Versão final apresentada em 05/08/2009 